IRA-International Journal of Applied Sciences ISSN 2455-4499; Vol.09, Issue 01 (October 2017)

Pg. no. 9-12

Institute of Research Advances

https://research-advances.org/index.php/IRAJAS

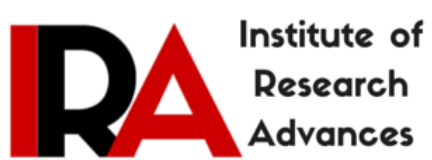

\title{
Cytogenetics and Importance of Genetic Counselling in Recurrent Pregnancy Losses: Experience from Tertiary Care Laboratory
}

\author{
Dr. Shailesh Pande ${ }^{1}$ Dr. Anurita Pais ${ }^{2}$ Gauri Pradhan ${ }^{3}$ Yamini Jadhav $^{4}$ Chaitali Parab ${ }^{5}$ \\ Bharat Kalthe $^{6}$ Sunmeet Matkar ${ }^{7}$ \\ $1,2,3,4,5,6,7$ Department of Cytogenetics and Medical Communications, Metropolis Healthcare Ltd, \\ Mumbai, India.
}

Type of Review: Peer Reviewed.

DOI: http://dx.doi.org/10.21013/jas.v9.n1.p2

\section{How to cite this paper:}

Pande, S., Pais, A., Pradhan, G., Jadhav, Y., Parab, C., Kalthe, B., Matkar, S. (2017). Cytogenetics and Importance of Genetic Counselling in Recurrent Pregnancy Losses: Experience from Tertiary Care Laboratory. IRA International Journal of Applied Sciences (ISSN 2455-4499), 9(1), 9-12. doi:http://dx.doi.org/10.21013/jas.v9.n1.p2

(C) Institute of Research Advances.

\section{(cc) BY-No}

This work is licensed under a Creative Commons Attribution-Non Commercial 4.0 International License subject to proper citation to the publication source of the work.

Disclaimer: The scholarly papers as reviewed and published by the Institute of Research Advances (IRA) are the views and opinions of their respective authors and are not the views or opinions of the IRA. The IRA disclaims of any harm or loss caused due to the published content to any party.

Institute of Research Advances is an institutional publisher member of Publishers Inter Linking Association Inc. (PILA-CrossRef), USA. The institute is an institutional signatory to the Budapest Open Access Initiative, Hungary advocating the open access of scientific and scholarly knowledge. The Institute is a registered content provider under Open Access Initiative Protocol for Metadata Harvesting (OAI-PMH).

The journal is indexed \& included in CAS Source Index of Chemical Abstracts Service of American Chemical Society (USA), WorldCat Discovery Service (USA), CrossRef Metadata Search (USA), WorldCat (USA), OCLC (USA), Open J-Gate (India), EZB (Germany) Scilit (Switzerland), Airiti (China), Bielefeld Academic Search Engine (BASE) of Bielefeld University, Germany, PKP Index of Simon Fraser University, Canada. 


\begin{abstract}
Loss of pregnancy either naturally or by medical termination is a destructive experience to the couple, especially those experiencing recurrent pregnancy losses (RPL). It is important to rule out the genetic aspect as the cause of pregnancy wastages. This retrospective study aimed to determine the frequency of chromosomal abnormalities and its various cytogenetic types in the samples received by Metropolis Healthcare laboratory, Mumbai. This study was conducted on the samples referred for chromosomal karyotyping with a history of Bad Obstetric History $(\mathrm{BOH})$. The couples who had an experience of two or more pregnancy losses were included in this study. Out of the 2102 samples referred, chromosomal abnormality was recorded in 384 (18.27\%) cases. Out of chromosomal abnormal cases, 126 (5.99\%) patients had reciprocal translocations out of which 27 (21.43\%) were Robertsonian translocations. Inversion of chromosome 9 was seen in 81 (21.09\%) patients, while inversion $Y$ in 28 (7.29\%) patients, and polymorphic variation like increase in length of satellite or heterochromatic region recorded in almost $149(38.30 \%)$ patients. Cytogenetic evaluation of couples with recurrent pregnancy losses $(R P L)$ is very important as after knowing the parental chromosomal pattern appropriate counseling can be offered to know the risk of recurrence, option of prenatal diagnosis and also opens the option of reproduction in some cases. This will also help them to have a cytogenetically healthy baby. Since the cytogenetic abnormalities are usually familial, the close blood relatives may also be benefited once the abnormality is detected.
\end{abstract}

Keywords: BOH, Karyotype, FISH, Product of conception, recurrent pregnancy losses, Amniotic fluid

\title{
Introduction
}

Pregnancy loss is always an unpleasant experience to the couple. It is always associated with guilt, unhappiness and many times with depression. This is most common among the couples with recurrent pregnancy losses (RPL) along with additional concerns like secondary infertility, menstrual abnormalities, advancing maternal age or uterine fibroids. It is reported that spontaneous abortions accounts for around 15 to $20 \%$ of the total pregnancies losses Choi (2014). Almost in 50\% of the first trimester pregnancy losses, the cause is genetic and chromosomal aneuploidy being the major factor in these cases. The most commonly reported aneuploidies are monosomy X, trisomy 13/18/21 followed by trisomy 16/22(Stephenson and Kutteh 2007). Other autosomal trisomies are not uncommon. However, the chances of recurrence of free trisomy are almost negligible. The other sub group comprises of an unbalanced translocation in fetus, where it is usually transmitted from one of the parents with the balanced translocation. The parents/couple having balanced translocation may not show any clinical manifestation's since there is no loss or gain of genetic material. It is to be noted that such type of chromosomal abnormalities are familial and the same experience the close blood relatives may have to face Ren (2013). Therefore, it becomes very important to undertake cytogenetic evaluation and perform genetic counselling of the couple and other close family members of the respective couple with balanced translocation.

In the cases with RPL, evaluation of product of conception (POC) is very important. However, as compared to other body tissues the culture failure rate of POC is quite high and it is reported to be almost 20-27\% Campos-Galindo (2015). As the tissue is precious and repeat sample is not possible, cases where POC evaluation was not done or there was failure of POC culture, cytogenetic evaluation of couple with history of two more pregnancy losses is important to rule out the chromosomal factor as a cause of pregnancy loss.

\section{Methods and Materials}

This retrospective study was conducted between the term of two years i.e. from January-2015 to December-2016. Peripheral blood (2-3 ml) was collected in Sodium heparin Vacutainers from the total study patients $(\mathrm{n}=2102)$ with a history of two or more than two pregnancy losses. All the blood samples were subjected to GTG staining and banding, cultures were set \& analysed by GTG-banding at 450-550 band level and reported as per ISCN and CAP and NABL guidelines. A total of 20 metaphases were studied per case and wherever applicable, FISH test for confirmation was conducted. 


\section{Results}

Out of the 2102 samples analysed with history of two or more pregnancy losses, 126 (5.99\%) patients showed reciprocal translocation. Out of 126 patients with reciprocal translocation, $99(78.57 \%)$ cases were the translocation between autosomes and 27(21.43\%) were the Robertsonian translocation between two acrocentric chromosomes. Out of 126 cases, two couples were reported having reciprocal translocation in both the partner. Inversion of one of the chromosome 9 was reported to be a normal polymorphic variation and was observed in 81(21.09\%) cases. Out of 81 cases with inversion of 9 chromosome, 2 (2.47\%) couples had inversion of 9 in both the parents and $1(1.23 \%)$ case had inversion in both the chromosome 9. Inversion of chromosome $\mathrm{Y}$ was found in 28(7.29\%) cases. Around $149(38.30 \%$ ) cases showed polymorphic variations in the form increase or decrease in the length of satellite or increase in the length of heterochromatic region. Since, Metropolis Healthcare Ltd is a Global Reference Laboratory, samples for chromosomal abnormalities are received from all parts of India. This could be the reason for variation in the percentage of abnormality detected in our study and also because of the selection bias since only the highly suspected samples were referred to our laboratory for chromosomal studies.

Table 1: Frequency of chromosomal aberrations seen:

\begin{tabular}{|c|c|}
\hline Type of chromosomal abnormality & No. of cases (\%) \\
\hline Balanced translocations & $99(25.78 \%)$ \\
\hline Robertsonian translocations & $27(7.03 \%)$ \\
\hline Inversion of Chromosome 9 & $81(21.09 \%)$ \\
\hline Inversion of Chromosome Y & $28(7.29 \%)$ \\
\hline Other polymorphic variations & $149(38.30 \%)$ \\
\hline Total & 384 \\
\hline
\end{tabular}

Table 2: Frequency of polymorphic variations

\begin{tabular}{|c|c|}
\hline Type of polymorphic variation & No. of cases (\%) \\
\hline Inversion 9 & $81(31.40 \%)$ \\
\hline Inversion Y & $28(10.85 \%)$ \\
\hline Yqh+ & $10(3.88 \%)$ \\
\hline $13 \mathrm{ps}+$ & $19(7.36 \%)$ \\
\hline $14 \mathrm{ps}+$ & $22(8.53 \%)$ \\
\hline $15 \mathrm{ps}+$ & $20(7.75 \%)$ \\
\hline $21 \mathrm{ps}+$ & $26(10.08 \%)$ \\
\hline $22 \mathrm{ps}+$ & $10(3.88 \%)$ \\
\hline $15 \mathrm{p}-$ & $1(0.39 \%)$ \\
\hline $22 \mathrm{p}-$ & $1(0.39 \%)$ \\
\hline $1 \mathrm{qh}+$ & $9(3.49 \%)$ \\
\hline $9 \mathrm{qh}+$ & $21(8.14 \%)$ \\
\hline $16 \mathrm{qh}+$ & $10(3.88 \%)$ \\
\hline Total & 258 \\
\hline &
\end{tabular}

\section{Discussion}

POC is an ideal tissue for cytogenetic testing in cases with recurrent pregnancy losses (RPL) Grati (2013). Despite the normal karyotype of husband and wife, the possibility of a fetal chromosomal abnormality due to an error in cell division cannot be ruled. Also, the possibility of gonadal mosaicism, though small, cannot be ruled out. Therefore, evaluation of POC becomes critical to ascertain the genetic etiology behind the pregnancy loss. There are numerous aetiologies like infectious, immunological, anatomical and genetic causes identified for a pregnancy loss/ abortion. It has been reported that fetal chromosomal abnormalities are the most common cause in an early pregnancy loss and its contribution being almost 50\% among all the spontaneous abortions (SA) Bell (1999), (Bricker and Farquharson 2002). The chances of recurrence of free trisomy are almost negligible. Cases with fetal Robertsonian translocation or unbalanced translocation in fetus may be due to balanced translocation in parents. Therefore, to 
determine the mode of transmission i.e. whether it is a familial mode or de novo parental mode, a chromosomal study has been an important step before planning the subsequent pregnancy. In this retrospective study, a total of 2012 couples with a history of two or more pregnancy losses resulted that 126 patients reported balanced translocation. Out of 126 cases, 27 cases have Robertsonian translocation. It is to be noted that in these 126 cases, the option of prenatal diagnosis by either Chorionic villus sampling (CVS) at 10-12 weeks or amniocentesis at 16-18 weeks should be discussed to enable them to undertake an informed choice. Polymorphic variations have been included in this study because the association of such polymorphic variation though small is reported to be with fetal chromosomal aneuploidies.

\section{Conclusion}

Cytogenetic evaluation of couples with RPL helps the couple to understand the genetic etiology (if any) behind the pregnancy loss. Elucidating the type of chromosomal abnormality may help the couple to avoid an expensive and extensive work up, assist to understand the risk of recurrence, and, helps to know if any prenatal testing is required. Polymorphic variations have included in this study because, though minimal, its association with $\mathrm{BOH}$ has been reported in the literature.

\section{Acknowledgment}

The authors would like to express sincere gratitude towards Metropolis Healthcare Ltd, Mumbai for providing the essential facilities to carry out this research.

\section{Conflict of interest}

The authors report no conflict of interest amongst them.

\section{References}

[1] Choi, T., Lee, H., Park, W., Jeong, S., and Moon, H., (2014), Spontaneous abortion and recurrent miscarriage: A comparison of cytogenetic diagnosis in 250 cases, Obstet Gynecol Sci., 57(6), Pp 518-525.

[2] Stephenson, M., and Kutteh, W., (2007), Evaluation and management of recurrent early pregnancy loss, Clin Obstet Gynecol., 50, Pp 132-145.

[3] Ren, C., Liang, Y., Wei, F., Zhang, Y., and Chen, Z., (2013), Balanced translocation t(3;18)(p13;q22.3) and points mutation in the ZNF407 gene detected in patients with both moderate non-syndromic intellectual disability and autism, Biochimica et Biophysica Acta (BBA) - Molecular Basis of Disease., 1832(3), Pp 431-438.

[4] Campos-Galindo, I., García-Herrero, S., Ferro, J., Simón, C., and Rubio, C., (2015), Molecular analysis of products of conception obtained by hysteroembryoscopy from infertile couples, J Assist Reprod Genet., 32(5), Pp 839-848.

[5] Grati, F., Gomes, D., Ganesamoorthy, D., (2013), Application of a new molecular technique for the genetic evaluation of products of conception, Prenat Diagn., 33(1), Pp 32-41.

[6] Bell, K., Van Deerlin, P., Haddad, B., Feinberg, R., (1999), Cytogenetic diagnosis of "normal 46, XX" karyotypes in spontaneous abortions frequently may be misleading, Fertil Steril., 71(2), Pp 334-341.

[7] Bricker, L. and Farquharson, F. (2002), Types of pregnancy loss in recurrent miscarriage: implications for research and clinical practice, Human Reproduction., 17(5), Pp 1345-1350. 